Cad.Est.Ling., Campinas, (44):283-290, Jan./Jun. 2003

\title{
HIPERTEXTO E INTERTEXTUALIDADE
}

\author{
ANTONIO CARLOS XAVIER ${ }^{1}$ \\ (Universidade Federal de Pernambuco)
}

\begin{abstract}
This paper aims at reflecting on the presence of intertextuality in hypertexts on-line. Digital hyperlinks are fundamental instruments of reading on the Web. They achieve a complex process of interconnection of hypertexts. Then, intertextuality seems to me the essential characteristic of the hypertexts. They offers to the browsers more access and fast connectivety to some hypertexts on the digital network.
\end{abstract}

\section{INTRODUÇÃO}

O objetivo fundamental deste trabalho é refletir sobre o fenômeno da intertextualidade no hipertexto, enquanto tecnologia enunciativa que se atualiza no suporte digital e se interconecta instantaneamente com outros hipertextos on-line.

Atualmente dezoito milhões de brasileiros usam Internet. No mundo, mais de seiscentos milhões de pessoas utilizam aproximadamente duzentos milhões de computadores que estão interconectados entre os mais de cento e cinqüenta países que detêm domínio na Web. É inegável a velocidade de expansão da quantidade de usuários que têm navegado pelas páginas eletrônicas da rede mundial de computadores. Esse fato tem despertado cada vez mais o interesse da comunidade científica em geral para estudar os impactos sociais, econômicos e culturais advindos da chegada das tecnologias digitais de comunicação. Esse acentuado crescimento de usuários de Internet certamente tem levado especialistas em literatura, educação, comunicação, sociologia, psicologia (Tuman,1992; Strassmann,1997; Kantrowitz, 1997; Snyder, 1998; Moran \& Hawisher,1998; Kress, 1998; Joyce, 1988, Tapscott, 1999) e agora também lingüistas (Crystal, 2001; Marcuschi, 2002 e Xavier, 2002) a voltarem suas pesquisas para revelar quais as modificações intelectuais, afetivas e linguageiras apresentadas para o uso dos dispositivos informáticos na vida em sociedade.

${ }^{1} \mathrm{O}$ autor foi orientando da $\operatorname{Prof}^{\mathrm{a}} \mathrm{Dr}^{\mathrm{a}}$ Ingedore Koch na Unicamp entre os anos de 1999 a 2002 . Meus sinceros agradecimentos a essa brilhante intelectual e excelente pessoa que tem sido para todos nós, privilegiados por com ela conviver dentro ou fora da academia. 
Enquanto lingüista, enfocarei, obviamente, o fenômeno da linguagem, procurando explicitar as formas do processamento da intertextualidade realizada por leitores de hipertextos.

\section{DEFINIÇÃO DE HIPERTEXTO}

Trata-se de um construto multi-enunciativo produzido e processado sobre a tela do computador, que, emergindo no seio da atual Sociedade da Informação, surge como mais novo desafio a ser enfrentado em nossa contemporaneidade.

Theodore Nelson, cunhador do termo "Hipertexto", descreve-o em Literary Machine (1993) como uma tecnologia com a qual se pode religar as idéias e os dados, evidenciando uma dupla vocação do hipertexto: um sistema de organização de dados e um modo de pensar.

O Projeto Xanadu, de autoria de Nelson, buscava criar uma biblioteca universal que funcionasse como um sistema de publicação de informações baseado em hipertextos. Ele concebia o hipertexto como sendo, ao mesmo tempo, um sistema material e uma tecnologia intelectual, pela qual o agente humano interage com as informações que ele mesmo faz nascer de um percurso (navegação) virtual, modificando-as em função de suas representações sociais (sistemas de crenças, valores, ideologias) e suas demandas circunstanciais.

Para Ted Nelson, era necessário criar um mecanismo que desse ao usuário acesso total ao mundo do conhecimento, permitindo-lhe escolher entre vários caminhos de acesso e, assim, fazê-lo decidir livremente qual trilha hipertextual seguir de acordo com seus interesses e necessidades. Em seu Projeto Xanadu, a noção de hipertexto se liga basicamente a um sistema de escrita não-sequencial, que funcionaria da mesma forma que a mente humana, isto é, por associações, em que um item puxa outro, movendo-se, instantaneamente, para o próximo, em meio a uma complexa rede de caminhos, atalhos e encruzilhadas.

Mas o Projeto Xanadu não vingou, tendo sido concretizado, ainda na década de 1960, pelo engenheiro elétrico, Douglas Engelbart, considerado hoje uma lenda viva da informática. Além de inventar o mouse e as atuais janelas de interface, Engelbart construiu o NLS (oN Line System), um sistema baseado em hipertextos, nos quais textos, imagens e vídeos eram apresentados conjunta e interativamente. Esse sistema permitiu ao usuário acessar todos esses elementos semióticos de modo não-linear e colaborativo. Somente no início dos anos 1980 é que o sistema tornou-se comercializável.

Até a década de 1980, a rede de computadores era restrita a algumas universidades, a institutos de pesquisa e aos laboratórios das forças armadas dos Estados Unidos e de alguns poucos países da Europa. Até então, o uso se limitava à troca de documentos escritos e a curtas mensagens via correio eletrônico. Mas no início da década de 1990, o físico britânico Tim Berners-Lee, pesquisador do CERN (Laboratório Europeu de Física de Partícula - www.cern.ch) na Suíça, imaginou um programa que pudesse mostrar toda a informação - pública e pessoal - num mesmo 
ambiente virtual. Foi então que desenvolveu a World Wide Web (www) ou a "teia de alcance mundial", popularizando, em 1991, a Internet entre todos os setores da sociedade.

A Web, como é mais conhecida, consiste em uma aplicação dos recursos da hipermídia à Internet, combinando os mais variados modos enunciativos (texto verbal, imagem, animação, vídeo, som) em cenários tridimensionais exibidos em páginas eletrônicas. No início, a Web não possuía uma interface muito amigável ao usuário comum, problema que foi resolvido dois anos depois, em 1993, com a criação dos browsers ou navegadores, que são programas gráficos que permitem visualizar, de maneira mais fácil e agradável, textos, imagens e animações, além de serem capazes de reproduzir sons, músicas e vídeos.

Portanto, hipertextos são dispositivos digitais multimodais e semiolingüísticos (dotados de elementos verbais, imagéticos e sonoros) on-line, isto é, páginas eletrônicas que estão indexadas à Internet, interligadas e que possuem um domínio URL ou endereço eletrônico, na World Wide Web.

Trata-se de uma nova forma de apresentar, representar, articular e trabalhar, lingüística e cognitivamente, dados multiformes dispostos nas janelas digitais abertas na tela do computador ligado à grande rede. Ele gera, para o leitor, a possibilidade de acessar e absorver informações, multi-sensorial e sinestesicamente, momento em que todos os modos enunciativos (texto verbal, som e imagem) ali presentes funcionam, cooperativamente, para a efetivação da leitura hipertextual.

Enfim, o hipertexto é o espaço virtual inédito no qual tem lugar um modo digital de enunciar e construir sentido.

\section{HIPER-INTERTEXTUALIDADE INFINITA}

A inter-relação entre os dizeres é uma condição de existência de qualquer texto ou discurso, já que nada surge do nada. Assim, todo discurso remete a outros anteriores, alude a já-ditos escritos e textualizados em celulose, que formam uma espécie de "memória discursiva", da qual todos os autores têm necessariamente que lançar mão, a fim de conferirem aos seus próprios discursos racionalidade e sentido. Esses já-ditos "estocados" nessa "memória discursiva", por sua vez, vão gerar ditos futuros, modificados, mas não totalmente novos ou inéditos, perpetuando a cadeia de dizeres realizados e realizáveis por textos ou hipertextos em qualquer suporte de leitura.

Koch (1990:75-79) afirma que há dois tipos de intertextualidade: de forma e de conteúdo. A primeira ocorre quando o produtor de um dado texto repete expressões, enunciados e trechos de outros textos. Já a intertextualidade de conteúdo se realiza no interior de uma mesma cultura, por meio de textos de uma mesma época e áreas de conhecimento. A intertextualidade de conteúdo pode se dar explícita ou implicitamente.

No caso de hipertextos, é mais freqüente ocorrer a intertextualidade explícita, já que os hiperlinks são estrategicamente construídos para levar o hiperleitor a lugares outros na rede. Lê-se um hipertexto navegando pelos textos verbais, imagens e figuras estáticas e dinâmicas nele ancorados. Ao abordá-lo, o hiperleitor pode lê-lo linearmente 
do início ao fim dentro de um mesmo site ou pode realizar desvios pelos hiperlinks, explorando as digressões. Os hiperlinks, espalhados pela superfície das páginas eletrônicas, estão prontos para serem acionados. Uma vez postos em operação, abre-se espaço virtual para o encadeamento da hiper-intertextualidade que vai se enovelando até o infinito virtual.

Não se pode dizer que exista um hipertexto principal no sentido forte deste termo; não há um hipertexto central ou mesmo algum centro ou núcleo em qualquer hipertexto on-line. Por essa razão, a intertextualidade explícita é uma das características mais fortes desta tecnologia enunciativa. Todo discurso, uma vez digitalizado e indexado à rede, ganha ubiqüidade, pode estar virtualmente em todos os lugares ao mesmo tempo. Por outro lado, na rede, todo discurso perde o direito de propriedade, abre mão da exclusividade de pertencer a um único autor. Os dizeres passam a pertencer a todos por estarem acessíveis a qualquer leitor que esteja em qualquer lugar do mundo conectado à Internet, o qual, por um simples clicar-de-mouse, se apossa do discurso do outro incluindo-o, através de um hiperlink, em seu próprio website.

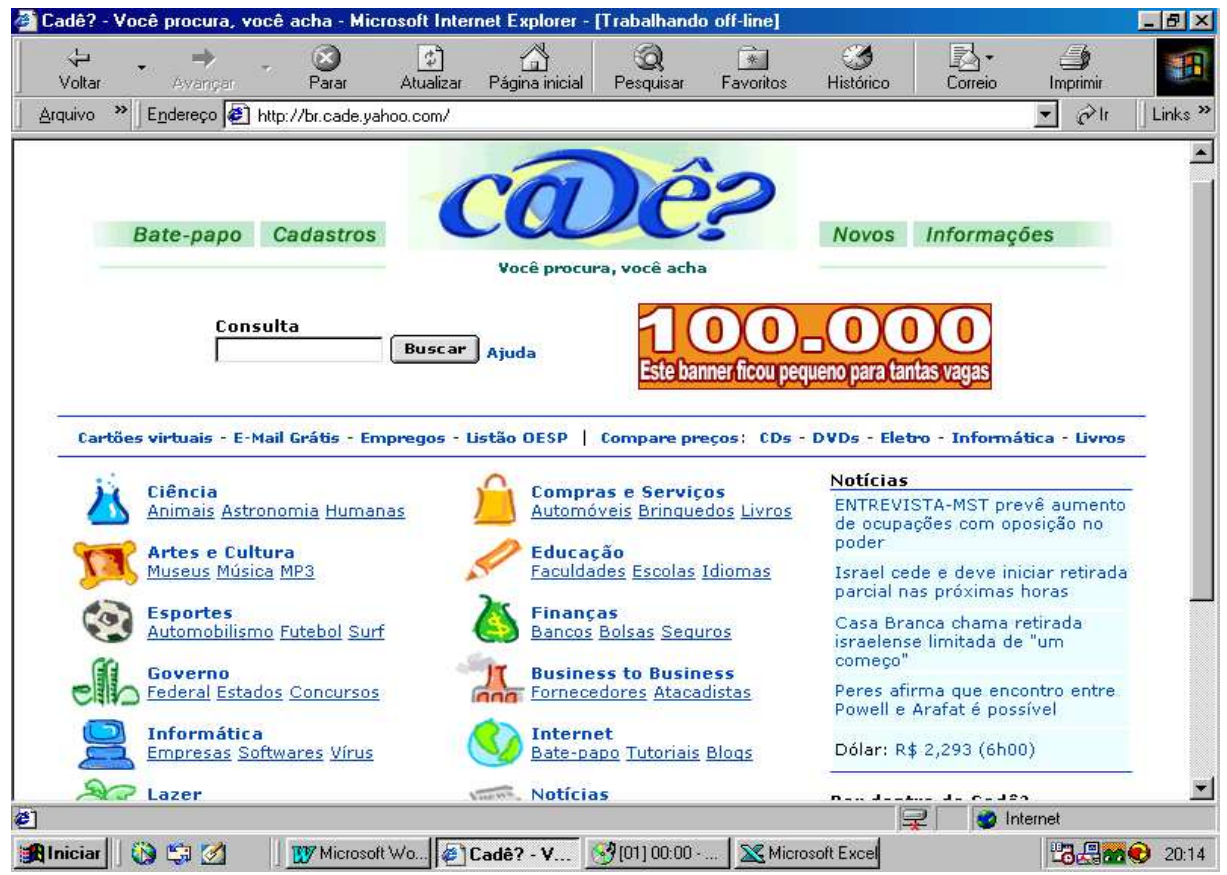

Tome-se como ilustração a página inicial do serviço de busca Cadê (www.cade.com.br). Nela se pode encontrar um universo de informações sobre uma grande variedade de assuntos. Escrevendo-se a palavra-chave da informação desejada no campo reservado para tal, chega-se a uma enorme quantidade de páginas $W e b$, onde aquela palavra tenha sido usada. Por se tratar de um mecanismo automatizado, que faz uma varredura lógico-procedural no banco de dados armazenado no servidor, é possível 
que salte à tela indicações de sites fora do contexto inicialmente desejado. Entretanto, o interessante é perceber a capacidade de interconexão deste mecanismo informático, o que sem dúvida permite a existência de uma conversação entre hipertextos que tratem dos mesmos assuntos ou não.

\section{HIPERLINK, COGNIÇÃO E ERUDIÇÃO}

Mas, na maioria dos hipertextos, são os hiperlinks que realizam a intertextualidade explícita, ou melhor, fazem acontecer a hiper-intertextualidade, já que viabilizam o diálogo instantâneo entre hipertextos on-line. Veja-se, por exemplo, o website pessoal do psicanalista Rubem Alves (www.rubemalves.com.br). Nele, encontram-se hiperlinks que levam o leitor (Xavier 2002:170-173) tanto para lugares dentro do mesmo domínio digital, (co-hipertextos), quanto para lugares fora daquele site (pan-hipertextos). Clicando-se sobre o enunciado "Se você gostou da minha casa", localizado dentro do quadro branco, à direita da página, o visitante sairá do hipertexto do escritor e realizará uma intertextualidade explícita ou hiper-intertextualidade. Isto porque esse hiperlink dá acesso ao site da empresa que confeccionou o website do psicanalista. Dentro da página eletrônica da www.dCON.com.br, evidentemente, há outros hiperlinks que se interligam com diversos sites e assim sucessivamente, formando uma grande rede de conexões perenes, uma grande malha hiperintertextualizada.

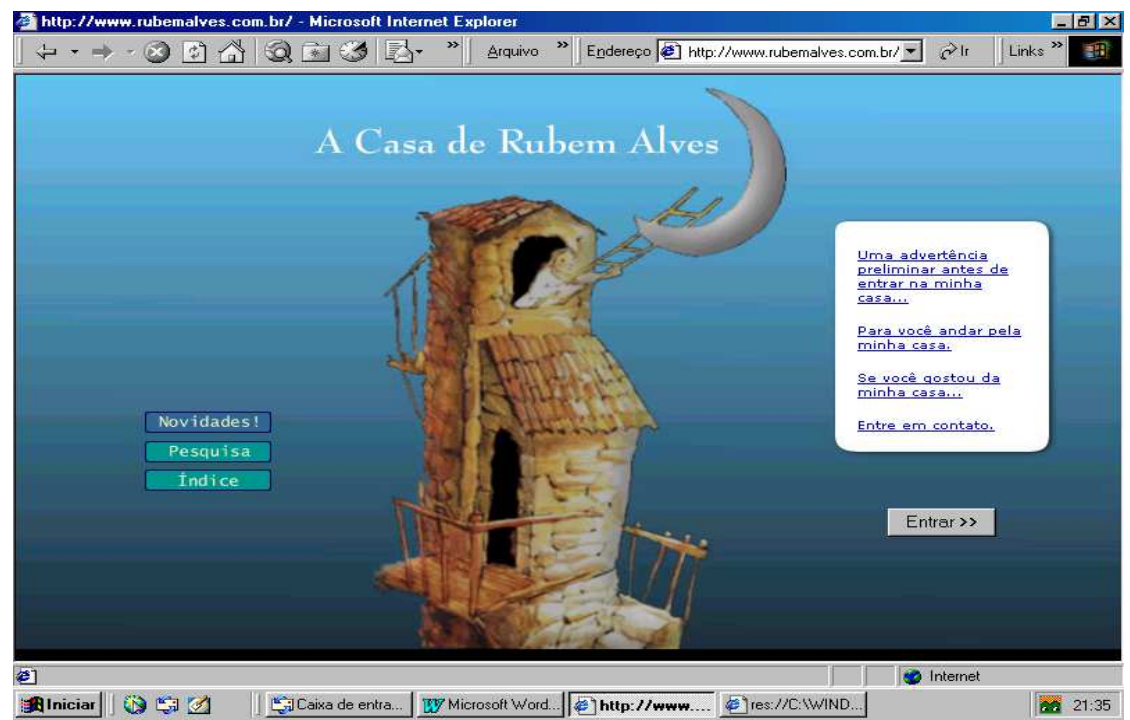

O hipertexto, veiculado pela Internet, parece ser o aporte digital e o espaço virtual que torna mais evidente este fenômeno da linguagem: a intertextualidade dos dizeres humanos. A tecnologia enunciativa do hipertexto acentua a função e as vantagens da 
intertextualidade na construção ou até mesmo na desconstrução do sentido de um discurso on-line.

Em tempos pós-modernos, o sentido desconstruído ou a ausência de sentido na perspectiva da lógica aristotélica-cartesiana parece ser a conclusão mais adequada a que podem chegar hiperleitores contemporâneos, depois de abordar alguns hipertextos e explorar aleatoriamente seus hiperlinks. Talvez essa seja uma atitude implicitamente desejada por alguns autores de hipertextos: fazer o hiperleitor encontrar o seu próprio sentido ao clicar sobre certos hiperlinks dependurados em certos websites. O suporte digital é o locus mais bem aparelhado para criar um leitor do tipo "flâneur" que vagueia pela Web sem compromisso prévio, "folheando" páginas eletrônicas sem objetivo definido, já que o hipertexto, por princípio, absorve tudo que possa ser expresso e representado pelo homem, através da linguagem verbal, da imagem e ou da sonoridade.

É possível afirmar, então, que toda conexão eletrônica é uma intertextualidade explícita, pois leva o hiperleitor a fazer uma hiper-intertextualidade. Ao clicar sobre um certo hiperlink, o navegador estará necessariamente se lançando para um outro hipertexto que, de alguma forma, terá relação com o hipertexto de onde partiu. Do ponto de vista do construtor de hipertextos, todos os hiperlinks seriam hiperintertextuais, pois teriam alguma razão de estar presentes na página $W e b$, até mesmo aqueles essencialmente divergentes.

Os hiperlinks conduzem, instantaneamente, o leitor a hipertextos, obras e discursos "originais", se indexados à rede, permitindo, dessa forma, o imediato acesso e a verificação das idéias de terceiros pelo próprio navegador. Essas "pontes virtuais" possibilitam vínculos intertextuais sem fim que só se assemelham a memórias privilegiadas de "eruditos" leitores de impresso.

Os hiperlinks aceleram o processamento da cognição humana que, pela faculdade da linguagem, faz associações imediatas de palavras por campos semânticos (sinônimos, hiperônimos, hipônimos, homônimos etc.), recorre a protótipos, aciona frames, quadros e planos de ação que entram em funcionamento quando se inicia a percepção sensorial de uma dada situação ou absorção de enunciados verbais. Os hiperlinks buscam auxiliar os nexos que devem ser feitos pelos leitores para ampliar seu horizonte de compreensão sobre o que está sendo focalizado na página $W e b$, sem, no entanto, impor o caminho "linkado" como o único a ser seguido. Eles atuam como as sinapses em nosso cérebro, promovendo as ligações necessárias entre as informações disponíveis até que se formem as primeiras inferências que possam nos levar a compreensão mais ampla de um acontecimento.

Ao mesmo tempo que pode ajudar o hiperleitor a construir o sentido do hipertexto, o hiperlink também pode atrapalhar sua concentração e distraí-lo para outras questões periféricas. Essa possibilidade também ocorre ao leitor de texto impresso, pois uma palavra ou expressão, mesmo sem destaque ou sublinhado, pode deixá-lo absorto; tudo vai depender de seu projeto de leitura, seus conhecimentos de mundo e de sua bagagem cultural seja diante de textos ou de hipertextos.

Em geral, o construtor de hipertextos inscreve nos hiperlinks a "erudição" necessária à compreensão parcial de um dado discurso, tornando público o que era 
apenas, potencialmente, dependente da "erudição" e da lembrança individuais de alguns poucos privilegiados leitores dotados de uma vasta gama de conhecimentos gerais.

\section{CONCLUSÃO}

Enfim, a arquitetura dos hipertextos e seus mecanismos técnicos de organização propiciam condições para a realização de intertextualidade explícita, pois os hiperlinks viabilizam o fluxo de migração entre hipertextos afins ou opostos, alimentando uma diálogo ininterrupto entre eles. Esse constante estado de passagem de um hipertexto a outro visa disponibilizar as informações relevantes a cerca de um tema discutido no website inicial, mas não garante que elas serão usadas "adequadamente" pelo hiperleitor. Às vezes o excesso de hiperlinks na mesma página eletrônica pode até prejudicar a leitura.

Em geral, tanto menos linear será a leitura no hipertexto, quanto maior for a disposição do usuário para vagar hiper-intertextualmente pelas informações "linkadas" e quanto mais livre de uma interpretação fechada for o campo do saber pelo qual o usuário decide trafegar durante sua leitura na tela digital. A especificidade da leitura no hipertexto está, exatamente, na falta de compromisso com uma ordem hierárquica instituída pela linearidade da própria língua que estrutura a leitura da maioria dos textos impressos, e que agora tem sido posta em questão. A intertextualidade se constitui, pois, tanto como uma característica dos textos humanos em geral quanto uma marca essencial de hipertextos. Nestes, por estar tão explícita, a intertextualidade pode ser prejudicial ao processo de compreensão, uma vez que pode levar o navegador a abandonar a hiperleitura iniciada.

Portanto, o hipertexto parece só se deixar "decifrar" fragmentariamente, funcionando como uma "materialidade discursiva", ao mesmo tempo, volátil e plural, cuja inteligibilidade é conquistada, lentamente, através das hiper-intertextualidades realizadas por mergulhos em hiperlinks que abrem infinitas portas para outros e outros dizeres hiper-intertextualizáveis.

\section{BIBLIOGRAFIA}

JOYCE, S. (1995). Siren Shapes; Exploratory and Constructive Hypertext, In:JOYCE, M. Of two minds: Hypertext Pedagogy and Poetics. Ann Arbor: University of Michigan Press.

KANTROWITZ, B. (1997). The information gap. In: HAWISHER, G. \& SELFE, C. Literacy, Technology and Society: confronting the issues. New Jersey: Prentice-Hall.

KOCH, I.G.V. (1990). A Coerência textual. São Paulo: Contexto. . (2002). Desvelando os segredos do texto. São Paulo: Cortez.

KOCH, I.G. V. \& TRAVAGLIA, L. C. (1990). Coesão e coerência textual. São Paulo: Contexto. 
KRESS, G. (1998). Visual and verbal modes representation in electronically mediated communication: the potentials of new forms of text. In: SNYDER, I. Page to Screen. London: Routledge.

MARCUSCHI, L.A. (2000a). A Coerência no hipertexto. Recife - UFPE, mimeo. (2000b). Hipertexto: definições e visões. Recife-UFPE, mimeo.

(2002). Gêneros textuais emergentes e atividades lingüísticas no contexto da tecnologia digital. Recife, Mimeo.

MORAN, C. \& HAWISHER, G. E. (1998). The Society of Mind. New York:Simon and Schuter.

SNYDER, I. (1997). Hypertext. The Eletronic Labyrinth. Washington: New York University Press.

STRASSMAN, P. (1997). Information system and literacy. In: HAWISHER, G \& SELFE, C. Literacy, Technology and Society: confronting the issues. New Jersey: Prentice-Hall.

TAPSCOTT, D. (1999). Geração Digital. São Paulo: Macron Books.

TUMAN, M. (1992). Literacy online: the promise (and peril) of reading and writing with computers. London: University of Pittsburgh Press.

XAVIER, A.C. (2002). O Hipertexto na sociedade da informação: a constituição do modo de enunciação digital. Tese de doutorado, IEL/UNICAMP, em andamento.

A.C. (2001). Processos de referenciação no Hipertexto. In: Cadernos de Estudos Lingüísticos (41) pp.165-176, Campinas: IEL/UNICAMP.

. (2000a). Hipertexto: novo paradigma textual?. In: Investigações: Lingüística e Teoria Literária, Vol. 12 pp. 177-192. Recife: Editora da UFPE.

XAVIER, A.C. \& SANTOS, C. (2000b). O Texto eletrônico e os gêneros de discurso. In: VEREDAS: Revista de Estudos Lingüísticos, Vol. 4, ${ }^{0} 1$. Juiz de Fora: Editora da UFJF. 